\title{
WHICH PATIENTS SURGICALLY TREATED FOR UROLITHIASIS NEED NUTRITIONAL CARE?
}

\author{
V. Aparecida Leandro-Merhi' ${ }^{1,2}$, J.L. Braga de Aquino ${ }^{1,3}$, R. Marmirolit, L. Oliveira Reis ${ }^{1,3}$
}

\begin{abstract}
Introduction: The present study is justified by the interest of investigating the impact of nutritional status on urology patients. Objective: To investigate the nutritional status of urology patients and identify the risk factors associated with type of kidney stone. Method: This cross-sectional study assessed the nutritional status and energy and nutrient intakes of 175 hospitalized adult urology patients stratified as follows: patients submitted to percutaneous nephrolithotripsy (PN), patients submitted to endoscopic ureterolithotripsy (EU), and patients without kidney stones. All study variables were investigated as possible predictors of urologic diseases. Multinomial logistic regression analysis and the proportional odds model identified the factors associated with kidney stones. The significance level was set at 5\%. Results: Kidney stones were more common in females $(\mathrm{p}<0.0001)$, EU patients without nutritional risk according to the Nutritional Risk Screening (NRS) ( $\mathrm{p}=0.0061)$, patients with normal triceps skinfold thickness $(\mathrm{p}=0.015)$, and younger patients $(\mathrm{p}=0.0001)$. Patients hospitalized for longer periods ( $\mathrm{p}=0.0038)$ and older patients $(\mathrm{p}=0.0001)$ did not have kidney stones. In EU patients kidney stones were associated with being female $(\mathrm{p}<0.0001 ; \mathrm{OR}$ : 3.699; CI: 2.001; 6.838), having mid-upper arm muscle circumference between the 10th and 90th percentiles ( $p=0.0477$; OR: 3.164; CI: 1.012 ; 9.895), not being at nutritional risk according to the NRS ( $\mathrm{p}=0.0308$; OR: 3.265; IC: 1.116; 9.557), and being younger ( $\mathrm{p}=0.0008$; OR: 0.966 ; CI: 2.001; 6.838). Conclusion: PN patients seem to need nutritional assessment and follow-up, while patients with kidney stones smaller than one centimeter do not seem to need routine nutritional assessment.
\end{abstract}

Key words: Urologic disease, kidney stone, nutritional care, energy intake, sodium intake.

\section{Introduction}

Nutritional risk and malnutrition have been associated with longer hospital stays regardless of nutritional assessment instrument (1-3). An association between malnutrition and high hospital morbidity and mortality has also been found by a study that used the Nutritional Risk Screening (NRS) to investigate nutritional risk, reporting complications such as respiratory infection, fistula, and hyperglycemia, among others (4).

Although the nutritional status of hospital patients is widely investigated, few Brazilian studies have investigated the nutritional status of urology patients. Cerantola et al, 2013 (5), prospectively investigated the nutritional risk and complications of hospitalized urology patients in Switzerland. The authors (5) demonstrated the importance of nutritional assessment, especially by the NRS, for accurately predicting postoperative morbidity in urology patients. Moreover, ESPEN recommends using

1. Professor Doctor, graduate program in Health Sciences, Puc-Campinas-SPBrazil; 2. School of Nutrition, Puc-Campinas-SP-Brazil; 3. School of Medicine, Puc-Campinas-SP-Brazil; 4. Urologist, Hospital e Maternidade Celso Pierro, PucCampinas-SP-Brazil

Corresponding Author: Vânia Ap. Leandro-Merhi, Professor Doctor, graduate program in Health Sciences, Puc-Campinas-SP-Brazil, e-mail: valm@dglnet.com.br

Received June 3, 2015

Accepted for publication June 15, 2015 the NRS, a validated instrument, in hospital patients (6, 7 ). The NRS takes into account the patient's metabolic stress, energy intake, age, and body weight. On the other hand, Filipovic et al, 2010 (8), found that the Subjective Global Assessment (SGA) is more sensitive for predictors of nutritional risk.

The present study is justified by the interest of investigating the impact of nutritional status on urology patients. Hence, the study objective was to investigate the nutritional status of urology patients and then identify the risk factors associated with type of kidney stone.

\section{Sample and method}

This cross-sectional study assessed the nutritional status and energy and nutrient intakes of surgery ward urology patients shortly after hospital admission. The sample included 175 adults stratified as: patients with kidney stones measuring from 2.0 to $4.0 \mathrm{~cm} \quad(\mathrm{n}=35)$ submitted to percutaneous nephrolithotripsy (PN); patients with kidney stones measuring from 0.6 to 1.0 $\mathrm{cm}(\mathrm{n}=37)$ submitted to endoscopic ureterolithotripsy (EU); and patients without kidney stones $(n=103)$. The inclusion criteria were: having urologic disease, aged 
Table 1

Characteristics and comparisons of urology patients by treatment group

\begin{tabular}{|c|c|c|c|c|}
\hline Variables & PN N=35 & EU N=37 & No kidney stone $\mathrm{N}=103$ & P-value * \\
\hline LOHS (days) & $4.5 \pm 3.4(4.0)$ & $3.2 \pm 2.1(2.5)$ & $5.9 \pm 6.9(4.0)$ & $0.00381^{a}$ \\
\hline \multicolumn{5}{|l|}{$\mathrm{X} \pm \mathrm{SD}$ (median) } \\
\hline Age (years) & $51.3 \pm 12.2(50.0)$ & $46.9 \pm 13.8(49.0)$ & $58.2 \pm 15.2(59.0)$ & $0.00011 \mathrm{~b}$ \\
\hline \multicolumn{5}{|l|}{$\mathrm{X} \pm \mathrm{SD}$ (median) } \\
\hline EI / kcal & $1720.8 \pm 501.5$ (1779.9) & $1726.9 \pm 564.5(1670.0)$ & $1631.4 \pm 617.7(1611.0)$ & 0.571 \\
\hline \multicolumn{5}{|l|}{$\mathrm{X} \pm \mathrm{SD}$ (median) } \\
\hline PI (g/kg) & $1.2 \pm 0.4(1.2)$ & $1.2 \pm 0.5(1.2)$ & $1.1 \pm 0.5(1.1)$ & $0.50^{1}$ \\
\hline \multicolumn{5}{|l|}{$\mathrm{X} \pm \mathrm{SD}$ (median) } \\
\hline PI $(\%)$ & $22.3 \pm 7.0(22.0)$ & $21.5 \pm 7.2(20.3)$ & $21.4 \pm 9.4(20.0)$ & $0.51^{1}$ \\
\hline \multicolumn{5}{|l|}{$\mathrm{X} \pm \mathrm{SD}$ (median) } \\
\hline \multicolumn{5}{|l|}{ SI (mg) } \\
\hline $\mathrm{X} \pm \mathrm{SD}$ (median) & $2782.9 \pm 1829.1(2499.9)$ & $2822.1 \pm 1987.2(2520.0)$ & $2761.2 \pm 1489.7(2857.8)$ & $0.78^{1}$ \\
\hline BMI (kg/m2) & $26.9 \pm 5.1(27.1)$ & $26.4 \pm 5.4(24.4)$ & $27.2 \pm 5.2(26.8)$ & $0.54^{1}$ \\
\hline \multicolumn{5}{|l|}{$\mathrm{X} \pm \mathrm{SD}$ (median) } \\
\hline MUAC $\leq$ p10 & $7(20.0 \%)$ & $7(18.9 \%)$ & $16(15.5 \%)$ & $0.20^{2}$ \\
\hline MUAC $\geq$ p90 & $7(20.0 \%)$ & $2(5.4 \%)$ & $24(23.3 \%)$ & \\
\hline MUAC p10-p90 & $21(60.0 \%)$ & $28(75.7 \%)$ & $63(61.2 \%)$ & \\
\hline $\mathrm{TST} \leq \mathrm{p} 10$ & $5(14.3 \%)$ & $1(2.7 \%)$ & $6(5.9 \%)$ & $0.015^{3}$ \\
\hline $\mathrm{TST} \geq \mathrm{p} 90$ & $11(31.4 \%)$ & $5(13.5 \%)$ & $37(36.6 \%)$ & \\
\hline TST p10-p90 & $19(54.3 \%)$ & $31(83.8 \%)$ & $58(57.4 \%)$ & \\
\hline MUAMC $\leq \mathrm{p} 10$ & $9(25.7 \%)$ & $9(24.3 \%)$ & $24(23.8 \%)$ & $0.35^{2}$ \\
\hline MUAMC $\geq$ p90 & $2(5.7 \%)$ & $2(5.4 \%)$ & $16(15.8 \%)$ & \\
\hline MUAMC p10-p90 & $24(68.6 \%)$ & $26(70.3 \%)$ & $61(60.4 \%)$ & \\
\hline \multicolumn{5}{|l|}{ SGA } \\
\hline Well nourished & $33(94.3 \%)$ & $36(97.3 \%)$ & $91(88.3 \%)$ & $0.25^{3}$ \\
\hline Malnourished & $2(5.7 \%)$ & $1(2.7 \%)$ & $12(11.7 \%)$ & \\
\hline \multicolumn{5}{|l|}{ NRS } \\
\hline No risk & $31(88.6 \%)$ & $37(100.0 \%)$ & $84(81.6 \%)$ & $0.0061^{3}$ \\
\hline At risk & $4(11.4 \%)$ & - & $19(18.4 \%)$ & \\
\hline \multicolumn{5}{|l|}{ Gender } \\
\hline Female & $20(57.1 \%)$ & $20(54.1 \%)$ & $24(23.3 \%)$ & $<0.0001^{2}$ \\
\hline Male & $15(42.9 \%)$ & $17(45.9 \%)$ & $79(76.7 \%)$ & \\
\hline
\end{tabular}

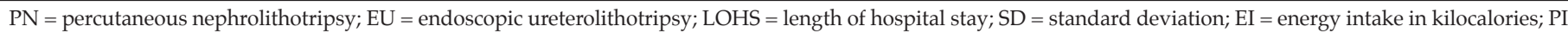

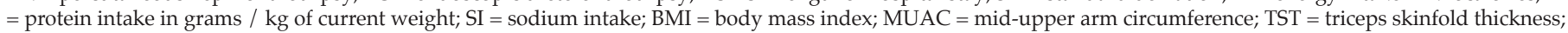

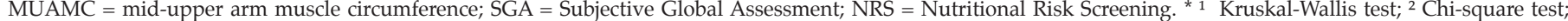

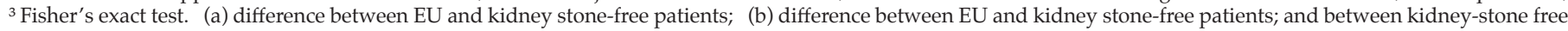
patients and PN.

more than 20 years, and complete clinical diagnosis and nutritional status assessment data in the medical record. Patients with severe diseases in terminal stages, with edema or ascites, undergoing hemodialysis, or bedridden were excluded. The study was conducted at Hospital e Maternidade Celso Pierro of the Pontifical Catholic University of Campinas-SP-Brazil, after approval of the local Research Ethics Committee ( ${ }^{\circ}$ 393.937).

Urologic disease data (PN, EU, and patients without kidney stones), length of hospital stay, age, gender, energy intake in kilocalories (EI/ kcal), protein intake, and sodium intake were collected and analyzed. Nutritional risk was determined by the NRS and nutritional status, by the SGA and the following anthropometric indicators: 
Table 2

Risk factors for type of kidney stone according to univariate multinomial logistic regression

\begin{tabular}{|c|c|c|c|c|}
\hline Variable & Reference & P-value & Odds ratio & CI $(95 \%)$ \\
\hline Age & & 0.0008 & $0.966(1.035)$ & $0.946 ; 0.986(1.014 ; 1.057)$ \\
\hline MUAC & $\leq \mathrm{p} 10$ & 0.6887 & 1.171 & $0.541 ; 2.537$ \\
\hline MUAC & $\geq \mathrm{p} 90$ & 0.1888 & 0.578 & $0.255 ; 1.309$ \\
\hline TST & $\leq \mathrm{p} 10$ & 0.0860 & 2.842 & $0.862 ; 9.367$ \\
\hline MUAMC & $\leq \mathrm{p} 10$ & 0.0843 & 2.958 & $0.864 ; 10.132$ \\
\hline MUAMC & p10-p90 & 0.0477 & 3.164 & $1.012 ; 9.895$ \\
\hline BMI & & 0.6383 & 0.985 & $0.924 ; 1.050$ \\
\hline SGA & Well-nourished vs malnourished & 0.1102 & 2.814 & $0.791 ; 10.016$ \\
\hline Protein intake $(\%)$ & & 0.6227 & 1.009 & $0.975 ; 1.044$ \\
\hline Sodium intake & & 0.8991 & 1.000 & $1.000 ; 1.000$ \\
\hline
\end{tabular}

MUAC $=$ mid-upper arm circumference; TST $=$ triceps skinfold thickness; MUAMC $=$ mid-upper arm muscle circumference; $\mathrm{BMI}=$ body mass index; SGA $=$ Subjective Global Assessment; NRS = Nutritional Risk Screening.

body mass index (BMI), mid-upper arm circumference (MUAC), triceps skinfold thickness (TST), and mid-upper arm muscle circumference (MUAMC).

The NRS classified nutritional risk according to weight loss, BMI, reduced energy intake, and disease severity as recommended by the literature $(6,7)$ as follows: at risk when score $\geq 3$ and without risk when score $<3$. Nutritional status classification by the SGA followed the standardization of the method (9), taking into account weight loss, food intake, and clinical and physical signs of malnutrition. The SGA classified patients as nourished and malnourished, which included mildly and moderately malnourished patients. No patient in our sample was severely malnourished.

The anthropometric indicators of adults and older adults were classified as recommended by the World Health Organization (WHO, 1998) (10) and Lipschitz (1994) (11), respectively. The body composition indicators MUAC, TST, and MUAMC were classified according to the reference percentile distribution standards for adults and older adults (12-14). The present study used MUAC and MUAMC values equal to or below the tenth percentile $(\leq \mathrm{P} 10)$ as indicators of lean mass depletion; values between the tenth and ninetieth percentiles (P10-P90) indicated lean mass preservation; and values equal to or above the ninetieth percentile ( $\geq$ P90) as above the reference standard for lean mass. TST equal to or below the tenth percentile $(\leq \mathrm{P} 10)$ indicated mass fat depletion; TST between the tenth and ninetieth percentiles (P10-P90) indicated fat mass preservation; and TST equal to or above the ninetieth percentile ( $\geq$ P90) indicated excess fat mass (12-14). Energy, nutrient, protein, and sodium intake data were obtained from a habitual food intake assessment and calculated by the software NutWin ${ }^{\circledR}(15)$.

All study variables were investigated as possible risk factors for kidney stones.

\section{Statistical analysis}

First the variables were analyzed descriptively using the chi-square test or Fisher's exact test when necessary to compare proportions. The Kruskal-Wallis test or analysis of variance (ANOVA) with rank transformation compared the numerical measures of the three groups of patients, followed by the Tukey test to locate the differences. All study variables were then investigated as possible predictors of urologic diseases. Univariate multinomial logistic regression analysis and proportional odds model identified the risk factors associated with the type of kidney stone. The significance level for all tests was set at 5\% (16-18).

\section{Results}

The study investigated the clinical characteristics, nutritional status, and energy and nutrient intakes of 175 urology patients divided into three groups: patients 
with kidney stones measuring from 2.0 to $4.0 \mathrm{~cm}(\mathrm{n}=35)$ submitted to percutaneous nephrolithotripsy (PN); patients with kidney stones measuring 0.6 to $1.0 \mathrm{~cm}$ $(n=37)$ submitted to endoscopic ureterolithotripsy (EU); and patients without kidney stones $(\mathrm{n}=103)$.

Table 1 shows the general description of the three groups of patients and compares them with regard to gender, age, length of hospital stay, nutritional status, energy intake, protein intake, and sodium intake.

The results show that kidney stones were more common in younger $(p=0.0001) \mathrm{EU}(\mathrm{p}=0.0061)$ females $(\mathrm{p}<0.0001)$ with normal TST $(\mathrm{p}=0.015)$ and without nutritional risk according to the NRS (Table 1). The nutritional status of the three groups according to the SGA did not differ. Patients without kidney stones were older $(\mathrm{p}=0.0001)$ and had longer hospital stays $(\mathrm{p}=0.0038)$.

Univariate multinomial logistic regression analysis investigated the risk factors associated with type of kidney stone (Table 2). EU patients were 3.7 times more likely to be female ( $<<0.0001$; OR: 3.699; CI: 2.001; 6.838); 3.1 times more likely to have MUAMC between P10 and P90 ( $\mathrm{p}=0.0477 ;$ OR: 3.164; CI: 1.012; 9.895); 3.2 times more likely not to be at nutritional risk by the NRS ( $\mathrm{p}=0.0308$; OR: 3.265; CI: 1.116; 9.557); and one time more likely to be younger ( $\mathrm{p}=0.0008$; OR: 0.966 ; CI: $2.001 ; 6.838$ ) (Table 2 ). The other study variables, namely energy intake, protein intake, sodium intake, and nutritional status according to the SGA, BMI, MUAC, and TST, were not risk factors for kidney stones.

\section{Discussion}

The present study investigated the nutritional status of urology patients because of this group's interest in the nutritional status and energy and nutrient intakes of this type of population.

Some $(11.4 \%)$ PN patients were at nutritional risk according to the NRS. On the other hand, no EU patient presented nutritional risk. The European Society of Clinical Nutrition and Metabolism (ESPEN) recommends the use of the NRS to assess the nutritional status of hospitalized patients (6). The NRS has been validated in a controlled clinical trial (7). However, $5.7 \%$ of the PN patients were malnourished according to the SGA. Interestingly, the prevalence of malnutrition or nutritional risk was greater in patients without kidney stones. None of the patients of the three groups were malnourished according to BMI, even though BMIrelated malnutrition has been frequently found by other studies in hospitalized patients $(19,20)$. Additionally, the mean BMI of the three groups did not differ, and BMI was not considered a risk factor for kidney stones. This may be due to fact that the three groups were overweight according to their mean BMI, in excess of 26 $\mathrm{kg} / \mathrm{m} 2$. Del Valle et al, 2012 (21), investigated the BMI of patients with kidney stones and found that 58.7\% were overweight or obese and that the proportion of overweight males was significantly higher. The authors concluded that the prevalence of hyperuricosuria and gouty diathesis increased significantly with BMI (21). However, urology patients at nutritional risk according to the NRS were at greater risk of postoperative complications (22). Karl et al, 2009 (23), prospectively studied urology patients and found that $16 \%$ were at nutritional risk according to the NRS and that older age, type of procedure, and malignant disease were determinants of nutritional risk. Using univariate and multivariate analysis, a recent study also found that urology patients at nutritional risk were more susceptible to postoperative complications (5).

Contrary to the expected, this study did not find a relationship between kidney stones and energy, protein, and sodium intakes, that is, the three groups of patients did not differ significantly. Recently, Awasthi et al, 2013 (24), assessed the family history of kidney stones and mineral intake of random patients with kidney stones and found that males' sodium, calcium, magnesium, and phosphorus intakes exceeded the recommended amounts; patients older than 45 years also had higher sodium, calcium, and magnesium intakes. Regression analysis also found that calcium and phosphorus intakes were significantly higher in male patients with kidney stones (24).

Sorensen et al, 2014 (25) reported that higher fruit, vegetable, and fiber intakes were associated with a lower incidence of kidney stones in postmenopausal women. The authors also found other protective effects regardless of the presence of known risk factors for kidney stones, but risk did not decrease in women with a history of kidney stones (25).

Malnutrition according to preoperative weight loss, BMI, and serum albumin is a strong and independent predictor of mortality and survival in urology patients 26 . Preoperative nutritional status is an important predictor of survival in urology patients (27).

The study strengths include the use of many nutritional status instruments and indicators to investigate the risk factors for kidney stones in hospitalized urology patients. This study of a Brazilian sample found that being female, younger, and at no nutritional risk according to the NRS, and having normal MUAMC were risk factors for kidney stones in urology patients. Other nutritional assessment studies of urology patients are necessary to determine whether nutritional risk, malnutrition, or even overweight or obesity can be risk factors for kidney stones in this group.

\section{Conclusion}

In conclusion, patients submitted to percutaneous nephrolithotripsy seem to need nutritional assessment and follow-up, and patients with kidney stones smaller than one centimeter do not seem to need routine 


\section{nutritional approach.}

Authorship declaration: All authors helped to collect data and write the manuscript.

Conflict of interests: The authors declare no conflicts of interest.

Acknowledgments: The authors thank the Pontifical Catholic University of Campinas (PUC-Campinas) for the opportunity of conducting this study.

\section{References}

1. Lee H, Cho YS, Jung S, Kim H. Effect of nutritional risk at admission on the length of hospital stay and mortality in gastrointestinal cancer patients. Clin Nutr Res 2013; 2:12-18.

2. Leandro-Merhi VA, Aquino JLB, Chagas JFS. Nutrition status and risk factors associated with length of hospital stay for surgical patients. Journal of Parenteral and Enteral Nutrition 2011; 35(2):241-248.

3. Almeida AL, Correia M, Camilo M, Ravasco P. Length of stay in surgical patients: nutritional predictive parameters revisited. Br J Nutr 2013; 109(2):322-8.

4. Mercadal-Orfila G, Lluch-Taltavull J, Campillo-Artero C, Torrent-Quetglas M. Association between nutritional risk based on the NRS-2002 test and hospital morbidity and mortality. Nutr Hosp 2012; 27(4):1248-1254.

5. Cerantola Y, Valerio M, Hubner M, Iglesias K, Vaucher L, Jichlinski P. Are patients at nutritional risk more prone to complications after major urological surgery ? The Journal of Urology 2013; 190(6): 2126-2132. doi: 10.1016/j. juro.2013.06.111.

6. Kondrup J, Allison SP, Elia M, Vellas B, Plauth M. ESPEN guidelines for nutrition screening 2002. Clinical Nutrition 2003; 22(4):415-21.

7. Kondrup J, Rasmussen HH, Hamberg O, Stanga Z, ESPEN Working Group Nutritional risk screening (NRS 2002): a new method based on a analysis of controlled clinical trials. Clinical Nutrition 2003; 22(3):321-336.

8. Filipovic BF, Gajic M, Milinic N, Milovanovic B, Filipovic BR, Cvetkovic M, Sibalic N. Comparison of two nutritional assessment methods in gastroenterology patients. World Journal of Gastroenterology 2010; 16(16):1999-2004.

9. Detsky AS, McLaughlin JR, Baker JP, Johnston N, Whittaker S, Mendelson RA, Jeejeebhoy KN. What is subjective global assessment of nutritional status? JPEN 1987; 11:8-13.

10. World Health Organization (WHO). Obesity: Preventing and managing the global epidemic - Report of a WHO Consultation on obesity. Geneva: WHO, 1998.

11. Lipschitz DA. Screening for nutritional status in the elderly. Prim Care 1994; 22(1): 55-67.

12. Frisancho AR. Anthropometric standards for the assessment of growth and nutritional status. Michigan: The University of Michigan Press; 1990.

13. Burr ML, Phillips MK. Anthropometric norms in the elderly. Br J Nutr 1984;
51:165-9.

14. Frisancho AR. New norms of upper limb fat muscle areas for assessment of nutritional status. Am J Clin Nutr. 1981; 34:2540-5.

15. Universidade Federal de São Paulo. Escola Paulista de Medicina. Programa de Apoio a Nutrição (NUTWIN) - programa de computador, versão 1.5. São Paulo: UNIFESP/ EPM; 2002

16. Conover WJ. (1999). Practical Nonparametric Statistics. $3^{\mathrm{a}}$ ed. John Wiley \& Sons Inc. Nova Iorque.

17. Hosmer DW, Lemeshow S. (1989). Applied Logistic Regression. John Wiley \& Sons Inc. Nova Iorque.

18. SAS System for Windows (Statistical Analysis System), versão 9.2. SAS Institute Inc, 2002-2008, Cary, NC, USA.

19. Amaral TF, Matos LC, Teixeira MA, Tavares MM, Álvares L, Antunes A. Undernutrition and associated factors among hospitalized patients. Clinical Nutrition 2010; 29(5):580-585.

20. Pirlich M, Schutz T, Norman K, Gastell S, Lubke HJ, Bischoff SC, et al. The German hospital malnutrition study. Clinical Nutrition 2006; 25(4): 563-72.

21. Del Valle EE, Negri AL, Spivacow FR, Rosende G, Forrester M, Pinduli I. Metabolic diagnosis in stone formers in relation to body mass index. Urol Res. 2012; 40(1):47-52. doi: 10.1007/ s00240-011-0392-8.

22. Karl A, Staehler M, Bauer R, Tritschler S, Hocaoglu Y, Buchner A, Hoffmann J, Kuppinger D, Stief C, Rittler P. Malnutrition and clinical outcome in urological patients. Eur J Med Res. 2011; 16(10):469-72. doi: 10.1186/2047783X-16-10-469.

23. Karl A, Rittler P, Buchner A, Fradet V, Speer R, Walther S, Stief GC. Prospective assessment of malnutrition in urologic patients. Urology 2009; 73(5):1072-6. doi: 10.1016/j.urology.2008.12.037.

24. Awasthi M, Malhotra SR. Assessment of mineral intake by kidney stone patients of Kangra District, Himachal Pradesh with respect to their gender, age and income. Indian J Pediatr. 2013;80(12):996-1001. doi: 10.1007/s12098013-0993-z.

25. Sorensen MD, Hsi RS, Chi T, Shara N, Wactawski-Wende J, Kahn AJ, Wang H, Hou L, Stoller ML; Women's Health Initiative Writing Group. Dietary intake of fiber, fruit and vegetables decreases the risk of incident kidney stones in women: a Women's Health Initiative report. J Urol. 2014;192(6):1694-9. doi: 10.1016/j.juro.2014.05.086

26. Gregg JR, Cookson MS, Phillips S, Salem S, Chang SS, Clark PE, Davis R, Stimson CJ Jr, Aghazadeh M, Smith JA Jr, Barocas DA. Effect of preoperative nutritional deficiency on mortality after radical cystectomy for bladder cancer. J Urol. 2011; 185(1):90-6. doi: 10.1016/j.juro.2010.09.021

27. Todd M. Morgan, Dominic Tang, Kelly L. Stratton, Daniel A. Barocas, Christopher B. Anderson, Justin R. Gregg, Sam S. Chang, Michael S. Cookson, S. Duke Herrell, Joseph A. Smith, Jr., and Peter E. Clark. Preoperative Nutritional Status Is an Important Predictor of Survival in Patients Undergoing Surgery for Renal Cell Carcinoma. Eur Urol. 2011; 59(6): 923-928. doi: 10.1016/j. eururo.2011.01.034 